\title{
Rosiglitazone suppresses angiogenesis in multiple myeloma via downregulation of hypoxia-inducible factor-1 $\alpha$ and insulin-like growth factor-1 mRNA expression
}

\author{
MINGZHONG RUI ${ }^{1}$, ZHANPING HUANG $^{1}$, YING LIU $^{1}$, ZIYAN WANG $^{1}$, \\ RUI LIU ${ }^{1}$, JINXIANG FU ${ }^{1}$ and HAIWEN HUANG ${ }^{1,2}$ \\ ${ }^{1}$ Department of Hematology, The Second Affiliated Hospital of Soochow University, Suzhou, Jiangsu 215004; \\ ${ }^{2}$ Department of Hematology, Jiangsu Institute of Hematology, The First Affiliated Hospital of \\ Soochow University, Suzhou, Jiangsu 215006, P.R. China
}

Received September 16, 2013; Accepted April 14, 2014

DOI: $10.3892 / \mathrm{mmr} .2014 .2407$

\begin{abstract}
Rosiglitazone (RGZ) is a thiazolidinedione ligand of peroxisome proliferator-activated receptor- $\gamma$. Our previous studies have confirmed that RGZ possesses antitumoral properties. Bone marrow angiogenesis exhibits an important role in multiple myeloma (MM), and angiogenesis often correlates with the prognosis and disease burden of MM. However, to the best of our knowledge, inhibition of angiopoiesis by RGZ in MM has not yet been reported. The present study aimed to investigate whether RGZ prevents angiogenesis and the possible underlying mechanism of this effect in MM. RPMI-8226 cells, primary myeloma cells from patients with MM or mononuclear cells from healthy patients were treated with different concentrations of RGZ, and various biological responses were detected using MTT, reverse transcription-polymerase chain reaction and western blot assays. The expression levels of hypoxia-inducible transcription factor-1 $\alpha$ (HIF1 $\alpha)$ and insulin-like growth factor-1 (IGF1) were significantly increased in the RPMI-8226 cells and the primary myeloma cells from the patients with MM compared with those in the mononuclear cells from the healthy patients. The results also showed that RGZ was able to inhibit proliferation and reduce viability of RPMI-8226 cells in a concentration- and time-dependent manner. RGZ was able to concentration-dependently inhibit the expression of HIF1 $\alpha$ and IGF1 mRNA in RPMI-8226 and primary myeloma cells from patients with MM. RGZ also inhibited the expression of pAKT and downregulated the expression levels of phosphorylated extracellular signal-regulated kinase (ERK) in RPMI-8226 cells. The results suggested that RGZ inhibits
\end{abstract}

Correspondence to: Dr Haiwen Huang, Jiangsu Institute of Hematology, The First Affiliated Hospital of Soochow University, 188 Shizi Road, Suzhou, Jiangsu 215006, P.R. China

E-mail: sophiehhw@hotmail.com

Key words: rosiglitazone, multiple myeloma, angiogenesis, hypoxia-inducible factor- $1 \alpha$ and insulin-like growth factor-1 mRNA the angiopoiesis of tumors by interfering with the phosphatidylinositol 3-kinase/AKT and ERK signaling pathways.

\section{Introduction}

Multiple myeloma (MM) is an incurable plasma cell neoplasm; however, patient survival rates have improved in the last decade due to the introduction of several effective therapies, including thalidomide and bortezomib (1). These drugs are expensive and the wide clinical application is limited in China, thus the development of new drugs is important for the treatment of multiple myeloma. Bone marrow (BM) angiogenesis exhibits an important role in the pathogenesis and progression of MM (2). Inducers of angiogenesis in the BM microenvironment include insulin-like grow th factor-1 (IGF-1), vascular endothelial growth factor (VEGF), and hypoxia-inducible transcription factor-1 (HIF-1) (3). Thus far, angiogenesis is the best-documented biological consequence of aberrant HIF expression in MM. Studies have shown that there is a positive correlation between HIF-1 $\alpha$ expression and the levels of BM angiogenesis, and expression of VEGF and VEGF receptor in biopsy specimens of patients with MM (4). Overexpression of HIF-1 in MM cells significantly enhanced MM-induced angiogenesis in an in vivo xenograft model (5). Small interfering RNA-mediated knockdown of HIF-1 $\alpha$ expression in RPMI-8226 cells and CD138-positive MM cells significantly reduced MM-induced angiogenesis in vitro (6). HIF-1 activation promotes the aberrant production of VEGF by MM and angiogenesis, and is associated with a poor prognosis in patients with MM (7). IGF-1 has been shown to activate VEGF expression in MM (8). IGF-1 is a cytokine that exhibits a role in MM development and promotes angiogenesis (9). The serum levels of IGF-1 in patients with newly diagnosed $\mathrm{MM}$ are positively correlated with markers of angiogenesis, including VEGF (10).

Several studies have provided evidence that the levels of nuclear translocation of HIF-1 $\alpha$ are increased following stimulation with IGF-1 (11-13). IGF1 has been shown to promote VEGF secretion in the 5T33MM model via the mitogen-activated protein kinase kinase/extracellular signal-regulated 
kinase (ERK) signaling pathway, independent of phosphatidylinositol 3-kinase (PI3K) (14). IGF-1 has been shown to upregulate the levels of VEGF production via HIF-1 $\alpha$ in an AKT-dependent manner (15). A study has reported that the regulatory mechanism of HIF-1 activation is closely associated with ERK (16). HIF-1 $\alpha$ is phosphorylated in hypoxia via an ERK-dependent signaling pathway (17). HIF-1 is activated by increased levels of VEGF production and transactivation via the PI3K/AKT and mitogen-activated protein kinase kinase/ERK signaling pathways in breast cancer (18).

A previous study confirmed that rosiglitazone (RGZ), a thiazolidinedione ligand of the peroxisome proliferator-activated receptor- $\gamma$, can inhibit myeloma cell proliferation, cell cycle arrest, apoptosis and differentiation (19). The expression levels of IGF1-mRNA have been found to be reduced following RGZ treatment and the levels of IGF-1 secretion were suppressed (20). Treatment with RGZ can attenuate the activation and expression of HIF-1 (21). The present study demonstrated that RGZ reduces the expression of HIF-1 $\alpha$ and IGF1 mRNA in RPMI-8226 and primary myeloma cells from patients. In addition, the molecular mechanisms underlying its anti-angiogenic effects was investigated.

\section{Materials and methods}

Cell lines and reagents. The RPMI-8226 myeloma cell line was provided by Professor Xueguang Zhang (Institute of Biological Technology, Soochow University, China). Cells were maintained in RPMI-1640 supplemented with $10 \%$ fetal calf serum, $2 \mathrm{mM}$ glutamine and $1 \%$ penicillin/streptomycin (Gibco-BRL, Grand Island, NY, USA). Cells were cultured at $37^{\circ} \mathrm{C}$ in a humidified $5 \% \mathrm{CO}_{2}$ atmosphere and passaged every 2-3 days. RGZ was purchased and dissolved in dimethylsulfoxide (DMSO; Sigma-Aldrich, St. Louis, MO, USA). Anti-mouse phospho-AKT monoclonal antibody and anti-mouse phospho-ERK $1 / 2$ monoclonal antibody were purchased from Cell Signaling Technology, Inc. (Danvers, MA, USA) and glyceraldehyde-3-phosphate dehydrogenase (GAPDH) was purchased from Abcam (Cambridge, UK).

Cell viability assay. The viability of the cells was assessed by an MTT assay. Cells ( $2 \times 10^{4}$ cells/well) were seeded in a 96-well plate and treated with the vehicle control $(<0.1 \%$ DMSO $)$ or RGZ at various concentrations $(10,20$ or $40 \mu \mathrm{M})$. For the time course experiment, cells were incubated for 24,48 or $72 \mathrm{~h}$. A solution of $20 \mu \mathrm{l} /$ well (MTT, $5 \mathrm{mg} / \mathrm{ml}$; Sigma, St. Louis, MO, USA) was added to each well for the last $4 \mathrm{~h}$ of incubation. After $4 \mathrm{~h}$, the plate was centrifuged at $1,000 \mathrm{rpm}$ for $10 \mathrm{~min}$ the media removed and $150 \mu \mathrm{l}$ DMSO was added to each well to dissolve the precipitate. The plate was then read at $570 \mathrm{~nm}$ in an ELISA microplate reader (ELX800; Bio-Rad, Hercules, CA, USA). Five replicate wells were used for each analysis. A percentage of the viability of the controls was presented in culture conditions.

Isolation of BM cells from the patients. This study was approved by the Ethics Committee of the Second Affiliated Hospital of Soochow University and informed consent was obtained from all patients in accordance with the Declaration of Helsinki protocol. Mononuclear cells were freshly isolated

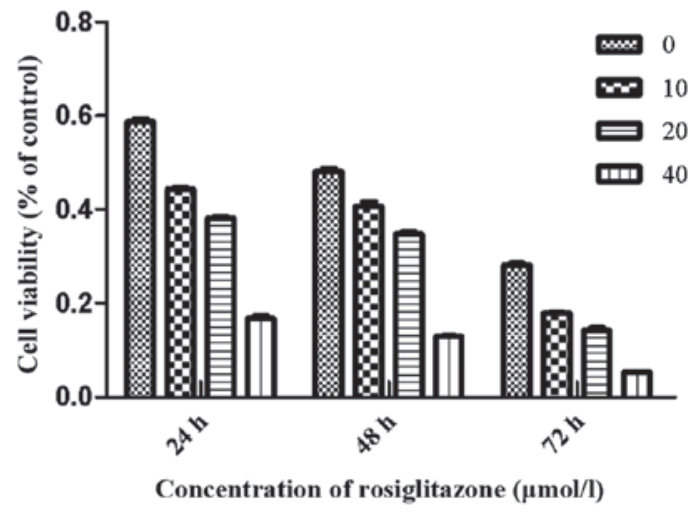

Figure 1. Rosiglitazone (RGZ) inhibited the growth of RPMI-8226 myeloma cells. Cells were treated with various concentrations of RGZ (0, 10, 20 and $40 \mu \mathrm{M}$ ) for different time periods. After 24,48 and $72 \mathrm{~h}$, cell viability was determined by an MTT assay. Results are representative of three experiments and each concentration was repeated five times in each experiment. Data are presented as the mean \pm standard deviation. Significance was determined by Student's t-test $\mathrm{P}<0.05$, compared with control.

from the BM of five patients with MM and five healthy patients by Ficoll-Hypaque density gradient centrifugation (Sigma). Myeloma cells were purified with the CD138 positive selection method using CD138 immunomagnetic beads and a magnetic cell sorter (AutoMACS; Miltenyi Biotec Ltd., Surrey, UK), according to the manufacturer's instructions. The primary CD138-positive myeloma cells were viable (95-97\%) in vitro. The cell density was maintained at $5 \times 10^{5} \mathrm{cell} / \mathrm{s} / \mathrm{ml}$ and cells were treated with RGZ at various concentrations (10, 20 or $40 \mu \mathrm{M}$ ) for $48 \mathrm{~h}$.

RNA extraction and reverse transcription-polymerase chain reaction. Total RNA was obtained from the cultured cells using TRIzol (Takara Bio, Inc., Shiga, Japan). Total RNA $(1 \mu \mathrm{g})$ was used for reverse transcription, which was performed with reverse transcriptase from Invitrogen Life Technologies (Carlsbad, CA, USA) at $65^{\circ} \mathrm{C}$ for $5 \mathrm{~min}, 42^{\circ} \mathrm{C}$ for $60 \mathrm{~min}$ and $70^{\circ} \mathrm{C}$ for $15 \mathrm{~min}$. Amplification started with a 5 min denaturation step at $95^{\circ} \mathrm{C}$, followed by 35 cycles of denaturation at $95^{\circ} \mathrm{C}$ for $15 \mathrm{sec}$ and annealing at $60^{\circ} \mathrm{C}$ for $45 \mathrm{sec}$ for HIF1 $\alpha$, or 35 cycles of denaturation at $95^{\circ} \mathrm{C}$ for $30 \mathrm{sec}$ and annealing at $55^{\circ} \mathrm{C}$ for $45 \mathrm{sec}$ for IGF1 and GAPDH. The sequences of the oligonucleotides used as specific primers for each gene were as follows: Forward: 5'-ACAAGTCACAGGACAG3' and reverse: 5'-AGGGAGAAAATCAAGTCG3' for HIF1 $\alpha$; forward: 5'-AGCAGTCTTCCAACCCAATTA3' and reverse: 5'-CACGGACAGAGCGAGCTG3' for IGF1; and forward: 5'-GTGGTCTCCTCTGACTTCAAC-3' and reverse: 5'-TCTCTTCCTCTTGTGCTCTTG-3' for GAPDH.

Western blot analysis. RPMI- 8226 cells $\left(1 \times 10^{6}\right)$ were seeded in six-well plates containing RPMI-1640 medium with $10 \%$ FBS and $1 \%$ antibiotics, and were then harvested $48 \mathrm{~h}$ after RGZ treatment. Following removal of the medium, the RPMI-8226 cells were washed twice with cold phosphate-buffered saline and lysed for $30 \mathrm{~min}$ in $100 \mu 1$ ice-cold cell-lysis buffer containing proteinase inhibitors $(1 \%$ cocktail and $1 \mathrm{mM}$ phenylmethylsulfonyl fluoride). The protein concentration was determined using a bicinchoninic acid 
A

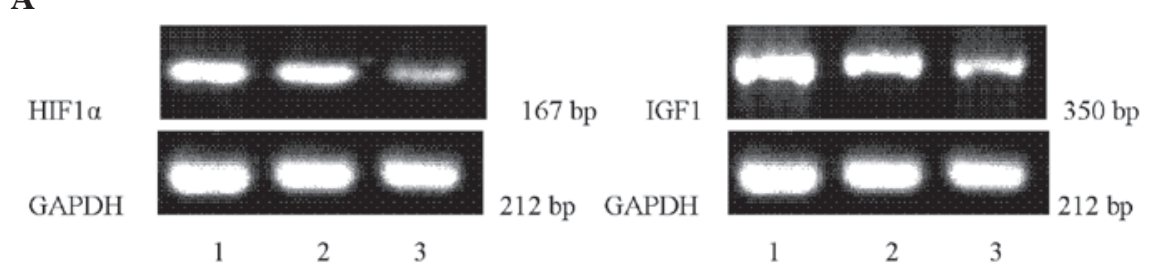

B
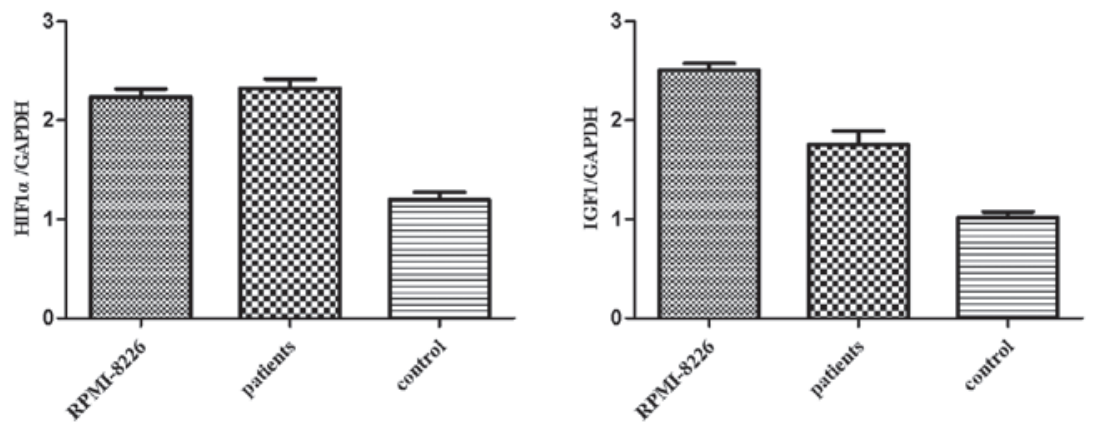

Figure 2. (A) mRNA expression levels of hypoxia-inducible transcription factor-1 $\alpha$ (HIF1 $\alpha$ ) and insulin-like growth factor-1 (IGF1). Lane 1, RPMI-8226 cells; lane 2, primary myeloma cells; and lane 3, healthy donor cells (control). (B) The relative mRNA levels of HIF1 $\alpha$ and IGF1. Glyceraldehyde-3-phosphate dehydrogenase (GAPDH) was used as the internal control. Data are presented as the mean \pm standard deviation. ${ }^{*} \mathrm{P}<0.05$, vs. the control.

assay. Protein samples $(50 \mu \mathrm{g})$ were denatured in $5 \mathrm{X}$ sodium dodecyl sulfate-polyacrylamide gel electrophoresis sample buffer and were subjected to sodium dodecyl sulfate-polyacrylamide gel electrophoresis on $10 \%$ Tris-glycine gels. The separated proteins were transferred onto polyvinylidene fluoride membranes for $1 \mathrm{~h}$ at $80 \mathrm{~V}$ using a Mini Trans-Blot Electrophoretic Transfer Cell (Bio-Rad). The membranes were blocked with $5 \%$ non-fat milk at room temperature for 1 h. Anti-phospho-AKT (Cell Signaling Technology, Inc.), anti-phospho-ERK 1/2 (Cell Signaling Technology, Inc.) and GAPDH (Abcam; dilution ratio 1:1,000) were used to probe the protein levels of the different desired molecules at $4{ }^{\circ} \mathrm{C}$ overnight. Further incubation with goat anti-mouse IgG peroxidase-conjugated secondary antibodies (Abcam) was conducted at room temperature for $2 \mathrm{~h}$. Protein bands were detected using an Enhanced Chemiluminescence kit (Amersham Biosciences, Little Chalfont, UK).

Statistical analysis. Statistical analysis was performed with the Statistical Program for Social Sciences software, version 19.0 (IBM, Armonk, NY, USA). All data are expressed as the mean \pm standard deviation. Analysis of variance was applied for comparison of the means of two or multiple groups, in which Student's t-test was further used for the comparison of two groups. $\mathrm{P}<0.05$ was considered to indicate a statistically significant difference.

\section{Results}

RGZ inhibits RPMI-8226 cell growth. To examine the effects of RGZ on myeloma cell growth, concentration- and time-response experiments were conducted. Cells were treated with RGZ at various concentrations dissolved in DMSO. After treatment with 10, 20 and $40 \mu \mathrm{mol} / 1 \mathrm{RGZ}$ for $48 \mathrm{~h}$, the viability of RPMI-8226 cells was $40.8 \pm 1.5,33.4 \pm 2.9$ and $11.9 \pm 1.1 \%$, respectively. After 24,48 and $72 \mathrm{~h}$ treatment with $20 \mu \mathrm{M}$ RGZ, the cell viability was $36.3 \pm 2.7,33.4 \pm 2.9$ and $14.3 \pm 2.4 \%$, respectively (Fig. 1). Higher levels of cell growth inhibition were observed at a RGZ concentration of $40 \mu \mathrm{M}$ after 24, 48 and $72 \mathrm{~h}$ compared with those of the cells treated with 10 or $20 \mu \mathrm{M}$ RGZ.

HIFI $\alpha$ and IGF1 $m R N A$ are expressed in primary myeloma, RPMI-8226 and healthy donor cells. Mononuclear cells were freshly isolated from the BM of healthy patients, RPMI-8226 cells and primary myeloma cells by Ficoll-Hypaque density gradient centrifugation. The results demonstrated that a higher expression of HIF1 $\alpha$ and IGF1 was detected in RPMI-8226 cells and primary myeloma cells compared with healthy donor cells (Fig. 2).

RGZ downregulates the expression of HIF $1 \alpha$ and IGF1 $m R N A$ in RPMI-8226 and primary myeloma cells. To determine whether HIF1 $\alpha$ and IGF1 expression is affected in myeloma cells isolated from patients with MM and RPMI-8226 cells after $48 \mathrm{~h}$ incubation with RGZ, the expression levels of the corresponding mRNA were measured using reverse transcription-polymerase chain reaction amplification. The HIF $1 \alpha$ and IGF1 gene expression levels were detected in the RPMI-8226 and primary myeloma cells. Following treatment with RGZ, the mRNA expression levels of HIF1 $\alpha$ and IGF1 were concentration-dependently downregulated compared with those in the untreated cells (Fig. 3). GAPDH mRNA was used as the control.

RGZ downregulates the functions of PI3K/AKT and ERK in RPMI-8226 cells. Based on the results shown in Fig. 4, RGZ was clearly able to inhibit pAKT and pERK expression after $48 \mathrm{~h}$ of treatment. When RPMI-8226 cells were cultured with various concentrations of RGZ for $48 \mathrm{~h}$, the expression levels of pAKT and pERK in the RPMI-8226 cells gradually decreased in a concentration-dependent manner. In the 

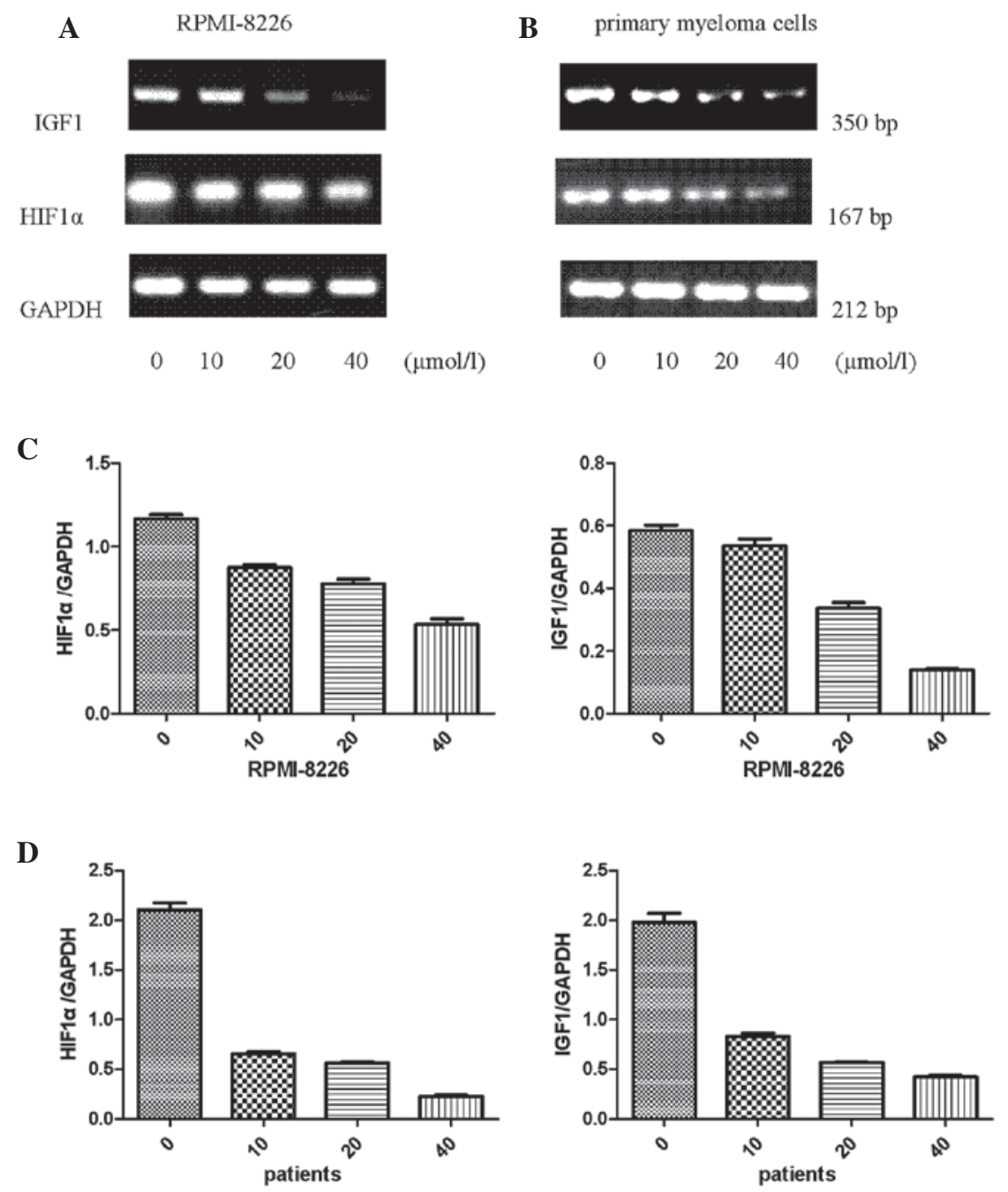

Concentration of rosiglitazone $(\mu \mathrm{mol} / \mathrm{l})$

Figure 3. Rosiglitazone (RGZ) induced the expression of hypoxia-inducible transcription factor-1 $\alpha$ (HIF1 $\alpha$ ) and insulin-like growth factor-1 (IGF1). Cells were incubated with $0,10,20$ and $40 \mu \mathrm{M}$ of RGZ for $48 \mathrm{~h}$. (A) RPMI-8226 cells and (B) primary myeloma cells were exposed to various concentrations of RGZ and the expression levels of HIF1 $\alpha$ and IGF1 were estimated by reverse transcription-polymerase chain reaction. Relative mRNA levels of HIF1 $\alpha$ and IGF1 in (C) RPMI-8226 cells and (D) primary myeloma cells. Glyceraldehyde-3-phosphate dehydrogenase (GAPDH) was used as the internal control. Data are presented as the mean \pm standard deviation. ${ }^{*} \mathrm{P}<0.05$, vs. the control.
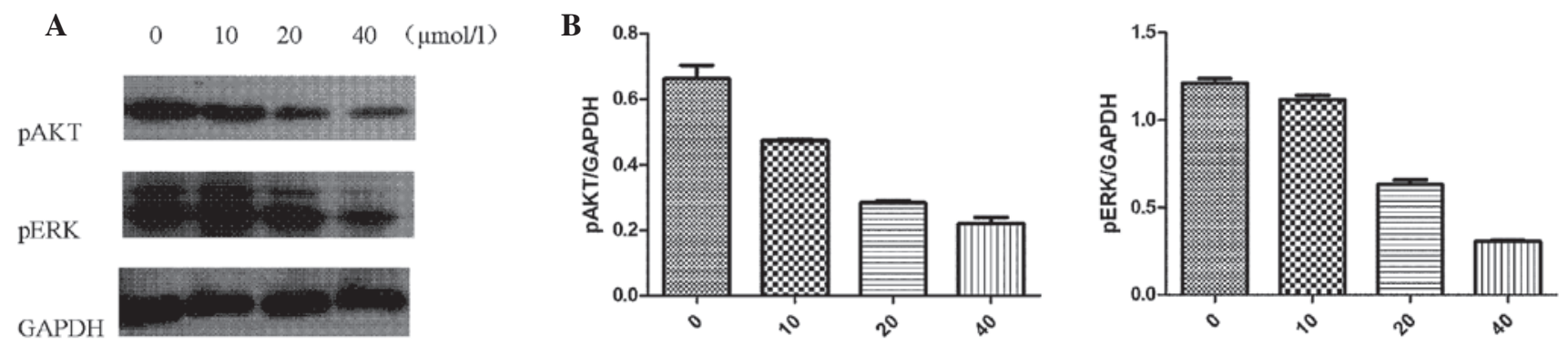

Concentration of rosiglitazone $(\mu \mathrm{mol} / \mathrm{l})$

Figure 4. Rosiglitazone (RGZ) treatment of RPMI-8226 cells reduced the levels of AKT and extracellular signal-regulated kinase (ERK) signaling. (A) Protein levels of pAKT and pERK. (B) Relative protein levels of pAKT and pERK. Glyceraldehyde-3-phosphate dehydrogenase (GAPDH) was used as the internal control. Data are presented as the mean \pm standard deviation. ${ }^{*} \mathrm{P}<0.05$, vs. the control.

RPMI-8226 cells treated for $48 \mathrm{~h}$ with $10 \mu \mathrm{M}$ RGZ incubation, the protein expression levels of pAKT and pERK were relatively lower compared with those of the control. When the RGZ concentration was increased to $20 \mu \mathrm{M}$, the protein expression levels of pAKT and pERK were further reduced. At the RGZ concentration of $40 \mu \mathrm{M}$, the pAKT and pERK 
protein expression levels were significantly lower compared with those of the control.

\section{Discussion}

A previous study confirmed that RGZ is able to induce cell cycle arrest, cell differentiation and apoptosis of MM cells (19). Numerous studies have shown that RGZ inhibits angiogenesis in various types of tumor, including human endometrial carcinoma (22), human ovarian cancer (23), lung cancer (24) and pancreatic carcinoma (25), and in other tissues, including in human umbilical vein endothelial cells (26). The present study assessed the inhibitory effects and molecular mechanisms of RGZ using RPMI-8226 myeloma cells and primary myeloma cells from patients. The MTT assay showed that RGZ inhibited the growth of RPMI-8226 cells in a time- and concentration-dependent manner. However, the optimal therapeutic strategy of targeting angiogenesis in MM with RGZ has not yet been identified. To the best of our knowledge, the present study reports for the first time, that RGZ has a potential antiangiogenic effect and may inhibit the PI3K/AKT and ERK signaling pathways in MM.

$\mathrm{BM}$ angiogenesis is important in the pathogenesis and progression of MM. The role of angiogenesis in growth, progression and metastatic spread of solid tumors has already been broadly confirmed (27). The progression of several cancers of hematopoietic lineages suggests a positive correlation between angiogenesis and progression, including that of non-Hodgkin's lymphoma, lymphoblastic leukemia, B-cell chronic lymphocytic leukemia, acute myeloid leukemia and MM (28). A study has also shown that BM angiogenesis is a hallmark of MM progression (29). Tumor angiogenesis mainly depends on growth factors that are released by neoplastic cells and are able to stimulate the growth of the blood vessels of the host, particularly those of endothelial cells (30). An increasing number of studies have found that HIF1 $\alpha$ and IGF1 exhibit a significant role in tumor angiogenesis. HIF1 $\alpha$ promotes the formation of blood vessels in MM $(7,4)$ and in other types of solid tumor, including bladder cancer (31), colon cancer (32) oral squamous cell carcinoma (33) and cervical carcinoma (34). IGF1 promotes angiogenesis in hepatocellular carcinoma (35) lung cancer (36) pancreatic ductal adenocarcinoma (37) and breast cancer (38).

In the present study, HIF1 $\alpha$ and IGF1 mRNA expression levels were significantly increased in RPMI-8226 and primary myeloma cells compared with those in healthy donor cells. The results have confirmed the data of previous studies $(3-5,10,39)$, which have suggested that high levels of HIF1 $\alpha$ and IGF1 contribute to angiogenesis and promote MM disease progression.

Several studies have shown that RGZ-induced activation of peroxisome proliferator-activated receptor- $\gamma$ inhibits angiogenesis in various types of tumor (22-25). Furthermore, it has been demonstrated that RGZ can suppress the levels of IGF-1 or HIF1 $\alpha$ expression in vitro and in vivo $(20,21)$. In the present study, when RPMI-8226 cells were incubated for $48 \mathrm{~h}$ with different concentrations of RGZ, the mRNA expression levels of HIF1 $\alpha$ and IGF1 were downregulated in a concentration-dependent manner. In particular, when the concentration of RGZ increased to $40 \mu \mathrm{M}$, the mRNA expression levels of HIF1 $\alpha$ and IGF1 were significantly reduced. Similar results were observed in CD138-positive myeloma cells from patients. These results suggest that when treated with RGZ, the expression levels of HIF1 $\alpha$ and IGF1 decreased significantly in a concentration-dependent manner. These results indicated that RGZ may inhibit angiogenesis in a concentration-dependent manner in RPMI-8226 and primary myeloma cells through downregulation of the expression levels of HIF1 $\alpha$ and IGF1.

A number of studies have suggested that the PI3K/AKT and ERK signaling pathways have an important role in angiogenesis (40-42). In a previous study, IGF-1 increased the expression levels of VEGF through the PI3K/AKT and ERK signaling pathways $(14,43)$. Other studies have suggested that HIF1 $\alpha$ promotes vascularization, which is mediated by the PI3K/AKT and MEK/ERK signaling pathways $(42,44)$. RGZ has been shown to exert an inhibitory effect on cell proliferation by downregulation of the PI3K/AKT and ERK1/2 signaling pathways $(45,46)$. Our previous study showed that RGZ can suppress IGF-1 or HIF1 $\alpha$ expression in RPMI-8226 and primary myeloma cells. Therefore, it was hypothesized that RGZ downregulates IGF-1 or HIF1 $\alpha$ expression levels through the PI3K/AKT and ERK signaling pathways. In the present study, when RPMI-8226 cells were cultured with various concentrations of RGZ for $48 \mathrm{~h}$, the expression levels of pAKT and pERK gradually decreased concentration-dependently. At an RGZ concentration of $40 \mu \mathrm{mol} / \mathrm{l}$, pAKT and pERK protein expression levels were significantly reduced compared with those in the untreated cells. Therefore, RGZ may inhibit IGF-1 or HIF1 $\alpha$ expression in a concentration-dependent manner through the PI3K/AKT and ERK signaling pathways.

In conclusion, a previous study has demonstrated that treatment with RGZ can induce growth inhibition in MM cells through cell cycle arrest, cell differentiation and apoptosis. The current study extends the data of previous studies to demonstrate that HIF1 $\alpha$ and IGF1 are highly expressed in primary myeloma cells and RPMI-8226 cells, and provides novel evidence that RGZ may inhibit angiogenesis concentration-dependently in RPMI-8226 cells and primary myeloma cells through downregulation of the expression levels of HIF1 $\alpha$ and IGF1. Furthermore, the findings of the present study provide additional evidence that RGZ may inhibit IGF-1 or HIF1 $\alpha$ expression concentration-dependently through the PI3K/AKT and ERK signaling pathways. Therefore, these findings suggest that the peroxisome proliferator-activated receptor- $\gamma$ ligand RGZ can be regarded as an angiogenesis inhibitor for the clinical treatment of myeloma and that it constitutes a promising therapeutic approach for patients with MM.

\section{Acknowledgements}

This study was supported by grants from the project of the Jiangsu Natural Science Foundation (no. BK2012610), The Colleges and universities Natural Science Fund of Jiangsu Province (no. SZ12306612) and The Social Development Fund of Suzhou City (no. SYS201134). The authors would like to thank all of the patients who provided samples for this study. 


\section{References}

1. Rajkumar SV: Treatment of multiple myeloma. Nat Rev Clin Oncol 8: 479-491, 2011.

2. Ribatti D, Vacca A, Dammacco F and English D: Angiogenesis and anti-angiogenesis in hematological malignancies. J Hematother Stem Cell Res 12: 11-22, 2003.

3. Ribatti D, Nico B and Vacca A: Importance of the bone marrow microenvironment in inducing the angiogenic response in multiple myeloma. Oncogene 25: 4257-4266, 2006.

4. Giatromanolaki A, Bai M, Margaritis D, et al: Hypoxia and activated VEGF/receptor pathway in multiple myeloma. Anticancer Res 30: 2831-2836, 2010.

5. Martin SK, Diamond P, Williams SA, et al: Hypoxia-inducible factor-2 is a novel regulator of aberrant CXCL12 expression in multiple myeloma plasma cells. Haematologica 95: 776-784, 2010.

6. Colla S, Storti P, Donofrio G, et al: Low bone marrow oxygen tension and hypoxia-inducible factor-1 $\alpha$ overexpression characterize patients with multiple myeloma: role on the transcriptional and proangiogenic profiles of CD138(+) cells. Leukemia 24 1967-1970, 2010.

7. Zhang J, Sattler M, Tonon G, et al: Targeting angiogenesis via a c-Myc/hypoxia-inducible factor-1alpha-dependent pathway in multiple myeloma. Cancer Res 69: 5082-5090, 2009.

8. Menu E, Jernberg-Wiklund H, De Raeve H, et al: Targeting the IGF-1R using picropodophyllin in the therapeutical 5T2MM mouse model of multiple myeloma: beneficial effects on tumor growth, angiogenesis, bone disease and survival. Int J Cancer 121: $1857-1861,2007$.

9. Menu E, van Valckenborgh E, van Camp B and Vanderkerken K: The role of the insulin-like growth factor 1 receptor axis in multiple myeloma. Arch Physiol Biochem 115: 49-57, 2009.

10. Pappa CA, Tsirakis G, Psarakis FE, Kolovou A, Tsigaridaki M, Stafylaki D, Sfiridaki K and Alexandrakis MG: Lack of correlation between angiogenic cytokines and serum insulin-like growth factor-1 in patients with multiple myeloma. Med Oncol Mar 30: 363, 2013.

11. Stoeltzing O, Liu W, Reinmuth $\mathrm{N}$, et al: Regulation of hypoxia-inducible factor-1alpha, vascular endothelial growth factor, and angiogenesis by an insulin-like growth factor-I receptor autocrine loop in human pancreatic cancer. Am J Pathol 163: 1001-1011, 2003.

12. Fukuda R, Hirota K, Fan F, et al: Insulin-like growth factor 1 induces hypoxia-inducible factorl-mediated vascular endothelial growth factor expression, which is dependent on MAP kinase and phosphatidylinositol 3-kinase signaling in colon cancer cells. J Biol Chem 277: 38205-38211, 2002.

13. Treins C, Giorgetti-Peraldi S, Murdaca J, et al: Regulation of hypoxia-inducible factor (HIF)-1 activity and expression of HIF hydroxylases in response to insulin-like growth factor I. Mol Endocrinol 19: 1304-1317, 2005.

14. Menu E, Kooijman R, Van Valckenborgh E, et al: Specific roles for the PI3K and the MEK-ERK pathway in IGF-1-stimulated chemotaxis, VEGF secretion and proliferation of multiple myeloma cells: study in the 5T33MM model. Br J Cancer 90: 1076-1083, 2004

15. Poulaki V, Mitsiades CS,McMullan C, et al: Regulation of vascular endothelial growth factor expression by insulin-like growth factor I in thyroid carcinomas. J Clin Endocrinol Metab 88: 5392-5398, 2003.

16. Sang N, Stiehl DP, Bohensky J, Leshchinsky I, Srinivas V and Caro J: MAPK signaling up-regulates the activity of hypoxia-inducible factors by its effects on p300. J Biol Chem 278: 14013-14019, 2003

17. Minet E, Arnould T, Michel G, Roland I, Mottet D, Raes M, Remacle J and Michiels C: ERK activation upon hypoxia: involvement in HIF-1 activation. FEBS Lett 468: 53-58, 2000.

18. Shi YH, Wang YX, Bingle L, Gong LH, Heng WJ, Li Y and Fang WG: In vitro study of HIF-1 activation and VEGF release by bFGF in the T47D breast cancer cell line under normoxic conditions: involvement of PI-3K/Akt and MEK1/ERK pathways. J Pathol 205: 530-536, 2005

19. Huang H, Wu D, Fu J, Chen G, Chang W, Chow HC, Leung AY and Liang R: All-trans retinoic acid can intensify the growth inhibition and differentiation induction effect of rosiglitazone on multiple myeloma cells. Eur J Haematol 83: 191-202, 2009.

20. Lecka-Czernik B, Ackert-Bicknell C, Adamo ML, et al: Activation of peroxisome proliferator-activated receptor gamma (PPARgamma) by rosiglitazone suppresses components of the insulin-like growth factor regulatory system in vitro and in vivo. Endocrinology 148: 903-911, 2007.
21. Kang BY, Kleinhenz JM, Murphy TC and Hart CM: The PPAR $\gamma$ ligand rosiglitazone attenuates hypoxia-induced endothelin signaling in vitro and in vivo. Am J Physiol Lung Cell Mol Physiol 301: L881-L891, 2011.

22. Nickkho-Amiry M, McVey R and Holland C: Peroxisome proliferator activated receptors modulate proliferation and angiogenesis in human endometrial carcinoma. Mol Cancer Res 10: 441-453, 2012

23. Yokoyama Y, Xin B, Shigeto T and Mizunuma H: Combination of ciglitazone, a peroxisome proliferator activated receptor gamma ligand, and cisplatin enhances the inhibition of growth of human ovarian cancers. J Cancer Res Clin Oncol 137: 1219-1228, 2011.

24. Reka AK, Goswami MT, Krishnapuram R, Standiford TJ and Keshamouni VG: Molecular cross-regulation between PPAR- $\gamma$ and other signaling pathways: implications for lung cancer therapy. Lung Cancer 72: 154-159, 2011.

25. Dong YW, Wang XP and Wu K: Suppression of pancreatic carcinoma growth by activating peroxisome proliferator-activated receptor gamma involves angiogenesis inhibition. World J Gastroenterol 15: 441-448, 2009.

26. Kim KY, Ahn JH and Cheon HG: Anti-angiogenic action of PPAR $\gamma$ ligand in human umbilical vein endothelial cells is mediated by PTEN upregulation and VEGFR-2 downregulation. Mol Cell Biochem 358: 375-385, 2011

27. Weidner N, Folkman J, Pozza F, Bevilacqua P, Allred EN, Moore DH, Meli S and Gasparini G: Tumor angiogenesis: a new significant and independent prognostic indicator in early-stage breast carcinoma. J Natl Cancer Inst 84: 1875-1887, 1992.

28. Bertolini F, Mancuso P, Gobbi A and Pruneri G: The thin red line: angiogenesis in normal and malignant hematopoiesis. Exp Hematol 28: 993-1000, 2000

29. Bhaskar A, Gupta R, Vishnubhatla S, Kumar L, Sharma A, Sharma MC, Das P and Thakur SC: Angiopoietins as biomarker of disease activity and response to therapy in multiple myeloma. Leuk Lymphoma 54: 1473-1478, 2013.

30. Ribatti D, Nico B, Crivellato E, Roccaro AM and Vacca A: The history of the angiogenic switch concept. Leukemia 21: 44-52, 2007.

31. Chen MC, Lee CF, Huang WH and Chou TC: Magnolol suppresses hypoxia-induced angiogenesis via inhibition of $\mathrm{HIF}-1 \alpha /$ VEGF signaling pathway in human bladder cancer cells. Biochem Pharmacol 85: 1278-1287, 2013.

32. Chen C, Cai S, Wang G, Cao X, Yang X, Luo X, Feng Y and $\mathrm{Hu}$ J: c-Myc enhances colon cancer cell-mediated angiogenesis through the regulation of HIF-1 $\alpha$. Biochem Biophys Res Commun 430: 505-511, 2013.

33. Zhou H, Fei W, Bai Y, Zhu S, Luo E, Chen K and Hu J: RNA interference-mediated downregulation of hypoxia-inducible factor-1 $\alpha$ inhibits angiogenesis and survival of oral squamous cell carcinoma in vitro and in vivo. Eur J Cancer Prev 21: 289-299, 2012.

34. Jeong JH, Jeong YJ, Cho HJ, et al: Ascochlorin inhibits growth factor-induced HIF-1 $\alpha$ activation and tumor-angiogenesis through the suppression of EGFR/ERK/p70S6K signaling pathway in human cervical carcinoma cells. J Cell Biochem 113: 1302-1313, 2012.

35. Chen Y, Gou X, Ke X, Cui H and Chen Z: Human tumor cells induce angiogenesis through positive feedback between CD147 and insulin-like growth factor-I. PLoS One 7: e40965, 2012.

36. Tsai AC, Pan SL, Lai CY, et al: The inhibition of angiogenesis and tumor growth by denbinobin is associated with the blocking of insulin-like growth factor-1 receptor signaling. J Nutr Biochem 22: 625-633, 2011

37. Nakamura K, Sasajima J, Mizukami Y, et al: Hedgehog promotes neovascularization in pancreatic cancers by regulating Ang-1 and IGF-1 expression in bone-marrow derived pro-angiogenic cells. PLoS One 5: e8824, 2010.

38. Tang X, Zhang Q, Shi S, Yen Y, Li X, Zhang Y,Zhou K and Le AD: Bisphosphonates suppress insulin-like growth factor 1-induced angiogenesis via the HIF-1alpha/VEGF signaling pathways in human breast cancer cells. Int J Cancer 126: 90-103, 2010.

39. Shushanov SS, Mar'ina LG, Kravtsova TA, Chernykh YB and Kakpakova ES: Coexpression of two mRNA isoforms of insulin-like growth factor-1 gene and mRNA of YB-1 gene in patients with multiple myeloma. Bull Exp Biol Med 154: 654-657, 2013.

40. Baek YY, Cho DH, Choe J, et al: Extracellular taurine induces angiogenesis by activating ERK-, Akt-, and FAK-dependent signal pathways. Eur J Pharmacol 674: 188-199, 2012. 
41. Chung $\mathrm{BH}$, Cho YL, Kim JD, et al: Promotion of direct angiogenesis in vitro and in vivo by Puerariae flos extract via activation of MEK/ERK-, PI3K/Akt/eNOS-, and Src/FAK-dependent pathways. Phytother Res 24: 934-940, 2010.

42. Shen K, Ji L, Gong C, Ma Y, Yang L, Fan Y, Hou M and Wang Z: Notoginsenoside Ft1 promotes angiogenesis via HIF-1 $\alpha$ mediated VEGF secretion and the regulation ofPI3K/AKT and Raf/MEK/ERK signaling pathways. Biochem Pharmacol 84: 784-792, 2012.

43. Zhu C, Qi X, Chen Y, Sun B, Dai Y and Gu Y: PI3K/Akt and MAPK/ERK1/2 signaling pathways are involved in IGF-1-induced VEGF-C upregulation in breast cancer. J Cancer Res Clin Oncol 137: 1587-1594, 2011.
44. Yang XM, Wang YS, Zhang J, et al: Role of PI3K/Akt and MEK/ERK in mediating hypoxia-induced expression of HIF-1alpha and VEGF in laser-induced rat choroidal neovascularization. Invest Ophthalmol Vis Sci 50: 1873-1879, 2009.

45. Choi IJ, Kim SY, Kwon CH and Kim YK: Rosiglitazone inhibits proliferation of renal proximal tubular cells via down-regulation of ERK and Akt. Ren Fail 32: 103-111, 2010.

46. Cantini G, Lombardi A, Piscitelli E, et al: Rosiglitazone inhibits adrenocortical cancer cell proliferation by interfering with the IGF-IR intracellular signaling. PPAR Res 2008: 904041, 2008. 